\title{
A integração de povos indígenas através de projetos de desenvolvimento comunitário: a política indigenista da FUNAl em finais dos anos de 1970 e início dos anos 1980
}

\author{
Accelerating indigenous people integration through \\ communitarian development projects: FUNAl indigenous \\ policy in the final 70's and early 80's
}

Joana A. Fernandes Silva ${ }^{1}$

DOI: http://dx.doi.org/10.20435/tellus.vi44.747

Resumo: O que apresento para esse dossiê é o Capítulo IV da minha dissertação de mestrado, intitulada Os Kaiowá e a ideologia dos projetos econômicos; juntamente com meu orientador, Mércio Pereira Gomes, fizemos uma incursão à política indigenista na década de 1970, cuja ênfase era na integração dos povos indígenas brasileiros ao mercado nacional. O conceito de aculturação fornecia a ótica a partir da qual as estratégias eram estruturadas. A partir das reflexões sobre o propósito de integração, lanço um olhar rápido sobre a política indigenista do governo atual.

Palavras chave: Kaiowá, economia, resistência, projetos de desenvolvimento.

Abstract: Here, to this dossier, I present chapter IV from my master's dissertation, Os Kaiowá e a ideologia dos projetos econômicos (Kaiowá and economical projects ideology); together with my advisor Mércio Pereira Gomes, we did an incursion to indigenous policy in the 80 's, whose emphasis was the integration of brazilian indigenous people into national market. Acculturation was the key concept through which such strategies were structured. Based on these considerations, I introduce a quick overview on current government indigenous policy.

Keywords: Kaiowá, economy, resistance, development projects.

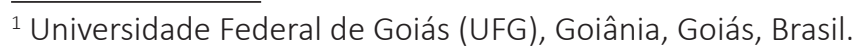




\section{INTRODUÇÃO}

O que apresento para esse dossiê é o Capitulo IV da minha dissertação de mestrado, intitulada Os Kaiowá e a ideologia dos projetos econômicos, defendida em novembro de 1982, em Antropologia Social, na Universidade de Campinas (UNICAMP). Sob a orientação do Prof. Dr. Mércio Pereira Gomes, fizemos uma incursão à política indigenista daquele período, cuja ênfase era na integração dos povos indígenas brasileiros ao mercado nacional. O conceito de aculturação fornecia a ótica a partir da qual as estratégias eram estruturadas.

Cursei meu mestrado no período da ditadura militar, período em que as universidades, alunos e professores eram pressionados, perseguidos e, muitas vezes, presos e torturados. Era um período tenso, de muito medo. Mas não era apenas o medo que imperava. Os efeitos desse período, na produção de uma pesquisa estão relatados logo abaixo.

O trabalho de campo e a exploração das fontes escritas eram dificultados pela repressão organizada pelos militares. A autorização Fundação Nacional do Índio (FUNAI) para pesquisar entre povos indígenas dependia de uma tramitação demorada. Nesse período a FUNAl era muito poderosa, os chefes dos postos indígenas tinham poder de polícia e, por ser subordinada ao Ministério do Interior (MINTER), engendrava uma política em consonância com os ideais ufanistas da década de 1970 no Brasil - desenvolvimento, ocupação da Amazônia, construção de estradas. Neste contexto, os povos indígenas eram vistos como povos à margem da história e do progresso e deveriam ser incorporados ao que os militares entendiam como desenvolvimento: não poderiam atrapalhar os caminhos que eram propostos pelo Ministério do Interior.

O trabalho nas fontes documentais era árduo. Havia apenas um arquivo da FUNAl em Campo Grande, em que pude obter alguns documentos. Surpreendi-me enormemente quando em 2013 realizei um laudo pericial em Laranjeira Ñanderu, com a copiosa documentação obtida na Universidade Federal de Dourados (UFGD) e no arquivo da Universidade Católica Dom Bosco (UCDB), em Campo Grande. As condições de pesquisa atualmente, com arquivos organizados e com a internet são infinitamente mais interessantes e ricas do que o eram em finais de 1970 e início de 1980. Mesmo o acesso à bibliografia atualmente é extremamente mais fácil. Reuni o que era acessível naquele momento e avalio que, juntadas as entrevistas 
que fiz com os Kaiowá de Panambi, em Dourados com gente que trabalhou para a Colônia Agrícola Nacional de Dourados (CAND), foi possível entender a dinâmica da expulsão dos Kaiowá de seu território. Naquele momento não se adivinhava, a partir de nossas conversas e da nossa convivência, que esse povo faria um vigoroso movimento para retomada de suas terras. Mas, relatos dos Kaiowá de Panambi sugeriam que havia muito mais gente do que aquela que estava nas reservas criadas pelo Serviço de Proteção ao Índio (SPI). O processo de perda era muito recente, os mais velhos haviam sofrido demais pela violência com que foram expulsos, as feridas eram muito abertas ainda. Ademais de serem exilados em pequenas reservas, havia ainda a afronta quase cotidiana, com as ameaças, com as roças queimadas, sobretudo em Panambizinho. Não se dormia em paz no período em que estive em trabalho de campo em Panambi e em Panambizinho e, provavelmente nem depois.

Para obtenção dos dados sobre a política dos projetos de desenvolvimento comunitário para todo o país e que estavam centralizados na FUNAI de Brasília, contei com a ajuda de uma antropóloga que trabalhava na sede. Ela desenvolveu o seguinte esquema para que eu pudesse ter acesso: me hospedou em sua casa, por 15 dias. Quando voltava do expediente diário me trazia, escondidos em uma bolsa, alguns volumes dos projetos destinados para povos específicos. Durante a noite eu colhia as informações e na manhã seguinte ela os devolvia, sem que ninguém percebesse. Dessa maneira, consegui obter uma visão geral da política desenvolvimentista elaborada pelo Ministério do Interior e executada pela FUNAI. A essa antropóloga eu devoto enorme gratidão. Claro que tínhamos medo de que ela fosse descoberta, expulsa da FUNAI e havia o risco de ser presa.

O trabalho de campo inicialmente foi um tanto difícil, porque os Kaiowá de Panambi e de Panambizinho não tinham referências agradáveis dos "carai" (não indígenas). Aos poucos foram me aceitando, duas famílias me acolheram amorosamente: a de Floreano e a de Paulito.

O capítulo IV, que trago aqui, pode ser considerado como um corte sincrônico na política indigenista do período militar e dos dados etnográficos apresentados. Embora um corte sincrônico, na perspectiva de um olhar situado em 2020, eu procurei entender os processos de contato enfrentados pelos Kaiowá da região de Dourados, onde a coleta da erva-mate teve um papel importante na história 
da violência sofrida pelos Kaiowá, que foi solapada pela política de ocupação do interior do Brasil, a partir da criação da Colônia Agrícola Nacional de Dourados em 1943, durante a Marcha para o Oeste.

Desafortunadamente, há uma atualidade no texto que trago aqui, pois a política de integração e de ataque à maneira com que os povos indígenas escolhem viver suas vidas, não cessaram. Os discursos provenientes do governo não mudaram, embora haja uma crueldade mais abertamente exposta. Se na década de 1970 e 1980 o Governo Federal estava comprometido, até certo ponto, com os ideais de humanitários e positivistas do Marechal Rondon, em 2020 não há mais esse compromisso. O que permanece é o projeto de liberação das terras indígenas; se até recentemente havia repulsa e veemente oposição à liberação das terras indígenas para mineração, garimpo e extração de madeira, o governo atual vem incentivando essas atividades que estão se traduzindo em invasões de garimpeiros e madeireiros.

O mote de que "os índios não podem atrapalhar o progresso e o desenvolvimento" não mudou. O que se entende por desenvolvimento?

O vice-presidente, Hamilton Mourão, declarou no dia 7 de agosto de 2020, que os povos indígenas têm "[...] direito a explorar as riquezas naturais das próprias terras, como a extração de metais e minerais preciosos, e usá-las para a agricultura e a pecuária", pois "[...] vivem em terras ricas como mendigos" (CAIXETA, 2020).

O presidente Jair Bolsonaro é o mais enfático quanto à integração dos povos indígenas e quanto ao desrespeito de suas terras e seu modo de viver. Abaixo estão algumas das suas declarações polêmicas e desrespeitosas:

"Vamos integrá-los à sociedade. Como o Exército faz um trabalho maravilhoso tocante a isso, incorporando índios, tá certo, às Forças Armadas" Globo News, 3 Agosto 2018 (1:25:33)

"Nosso projeto para o índio é fazê-lo igual a nós." Notícias UOL, 1 Dezembro de 2018

"Índio não fala nossa língua, não tem dinheiro, é um pobre coitado, tem que ser integrado à sociedade, não criado em zoológicos milionários." Midiamax, 22 Abril de 2015. (SURVIVAL, 2020).

Em uma análise rápida, percebe-se que o tom de agressividade contra os índios brasileiros aumentou, presidente e vice-presidente se sentem com licença para expressar seu preconceito e para negar direitos constitucionais. 
Mas, qual é o sentido desses ataques? A política apresentada nas páginas a seguir, mostra o esforço da FUNAI em levar o desenvolvimento e em transformar as economias indígenas para que sejam integradas ao sistema econômico hegemônico. Brighenti (2015) observa que: “A concepção de 'desenvolvimento' do Estado brasileiro está associada a ações agressivas contra o meio ambiente e suas populações originárias e tradicionais". O avanço a novos territórios responde a uma ideia de que é preciso expandir as riquezas e às pressões do agronegócio e essa expansão colide diretamente com os territórios indígenas.

A seguir, apresento o capítulo IV na íntegra, apenas com algumas pequenas atualizações, onde excluí o termo "tribo" que era corrente naquela época.

\section{2 “FAZER DO ÍNDIO, UM ÍNDIO MELHOR” (FUNAI)}

Os projetos de desenvolvimento comunitário são projetos econômicos implantados em diferentes comunidades indígenas consideradas pela FUNAI como em adiantado estado de aculturação. De acordo com a tipologia estabelecida pela FUNAI, grupos tribais em adiantado estado de aculturação são aqueles que mantêm uma certa relação com a economia regional (muitas vezes empregatícias) e que já adotaram certos traços da sociedade abrangente. Estes grupos têm sido os mais visados na implantação de projetos econômicos na medida em que se localizam em regiões de avançado grau de implantação do capitalismo no campo e sobre os quais a pressão da política de integração da FUNAl e do Ministério do Interior se fazem sentir mais fortes.

Como regra são reaproveitados os recursos econômicos e o potencial de produção do lugar onde vivem esses grupos: esses projetos são moldados (em termos do que vai ser produzido) de acordo com a economia regional, e os mesmos produtos que se destacam na produção regional vão ser produzidos dentro dos limites das aldeias. Em outros termos, os projetos de desenvolvimento comunitário são uma reprodução do sistema econômico regional, ligeiramente adaptados quanto à forma em que o trabalho é executado. Também são reaproveitados o que a FUNAI acredita que sejam os princípios da organização do grupo tribal em questão, como por exemplo, o chamado comunitarismo.

Os projetos econômicos podem ser voltados ao extrativismo, à agricultura e à pecuária, sendo que nos últimos anos a tônica tem sido nos projetos 
agrícolas. Uma grande massa de recursos financeiros é injetada dentro das aldeias, através de implementos agrícolas (tratores, colhedeiras), inseticidas, fertilizantes e etc. A mão de obra empregada nos trabalhos é paga através de um sistema que poderia assemelhar-se ao cooperativista, que é a entrega de uma quantia " $x$ " de alimentos em função do número de horas trabalhadas por cada homem.

\section{RETROSPECTIVA}

Esta retrospectiva é feita a partir de 1973, pois parece ser por essa época que a política de aplicação de projetos de desenvolvimento comunitário passa a receber atenção especial da FUNAI.

A FUNAI já em 1973 dividia os projetos de desenvolvimento comunitário em quatro áreas: bovinocultura, atividades agrícolas, atividade industrial e extrativismo vegetal.

O argumento da FUNAI, nesse período, era de que as demarcações das reservas

Visam não só as necessidades atuais dos grupos, como as formas de exploração da terra a serem implantadas no futuro. Essa preocupação objetiva de preservar a potencialidade para que, através da evolução natural das comunidades, venham a ser instalados processos de produção nessas áreas, de tal modo que as populações se tornem uma parcela economicamente ativa. (FUNAI, 1973, p. 57).

\subsection{Pecuária}

A pecuária neste período era tida como "[...] uma das atividades da mais alta significação para as economias indígenas e pode-se dizer, como a forma mais racional de ocupação do solo e consequente preservação das Reservas Indígenas" (FUNAI, 1973, p. 58).

Ainda em 1973, existia a instituição da Renda Indígena, que era utilizada para a implantação de projetos em áreas onde havia rebanhos maiores e para a manutenção de pequenos rebanhos que a FUNAI considerava como de subsistência. Estes rebanhos eram, em sua maioria, herança do Serviço de Proteção ao Índio. 
Embora conste do Boletim Informativo que o gado das aldeias indígenas era utilizado para a subsistência, sabe-se que era absolutamente controlado pela FUNAI, não podendo ser consumido normalmente: seu uso era e é restrito a datas oficiais como, por exemplo, o Dia do Índio, comemorado em 19 de abril. Deve ser assinalado que, embora o rebanho seja criado em território indígena, a decisão de abate de uma rês cabe ao chefe do posto indígena e a seus superiores, e ele quem decide qual a data, qual a quantidade de abates e como a carne vai ser distribuída.

Em 1973 havia apenas quatro projetos em fase de implantação: Fazenda São Marcos (Roraima), com um efetivo de quatro mil cabeças, iniciado em 1969. Eram previstos pelo projeto um rebanho de vinte mil cabeças; Ilha do Bananal (Goiás), com um efetivo de 3.500 cabeças, iniciado em 1970. Esperava-se pela capacidade da área onde estava o projeto, um aumento para 200 mil cabeças, através da introdução de 39 reprodutores da raça nelore; Bodoquena (Mato Grosso do Sul), que teve seu início em 1972, com um rebanho de 1500 cabeças e, pela potencialidade da área, esperava-se chegar a 100 mil cabeças. Esta parece ser a única área em que são abatidas duas ou três reses semanalmente para os Kadiweu².

\subsection{Atividades Agrícolas}

Em 1973, os projetos de desenvolvimento comunitário entram divididos entre econômicos e de subsistência. Os projetos econômicos têm fins comerciais, demandam grandes roças comunitárias enquanto os de subsistência tem o objetivo de dar assistências às lavouras familiais. De certa forma, os projetos de "subsistência" eram uma espécie de treinamento para os projetos econômicos. Estes projetos econômicos, de acordo com a FUNAI

Funcionam como verdadeiras escolas de capacitação de mão de obra nas comunidades, seja pelo engajamento de índios como operadores de maquinas agrícolas, seja pelo efeito indireto na introdução de novas técnicas de produção. (FUNAI, 1973, p. 63).

2 Esta informação foi dada por um encarregado da FUNAI que trabalhava com o rebanho de gado da Bodoquena, no ano de 1980. 
Em 1973, cinco projetos agrícolas estavam em fase de implantação:

1. Projeto de trigo e soja, no posto indígena Guarita (Rio Grande do Sul), com o plantio de uma área de 150 hectares.

2. Projeto de trigo e soja, no posto indígena Ligeiro (Rio Grande do Sul), com uma área de 150 hectares.

3. Projeto de trigo e soja, no posto indígena Doble (Rio Grande do Sul), em uma área de 50 hectares.

4. Projeto de Rizicultura, na Ilha do Bananal, com uma área de plantio de 130 hectares.

5. Projeto de trigo e soja, no posto indígena Chapecó (Santa Catarina), em uma área de 335 hectares.

No total, estes projetos ocupam 815 hectares de roças com fins comerciais. Havia, neste mesmo período, cinco projetos de subsistência nos postos indígenas de Mangueirinha, Guarita, Ligeiro e Carreteiro, no Rio Grande do Sul e nos postos indígenas Areões e Buriti em Mato Grosso.

\subsection{Atividade Industrial}

A única atividade industrial nas áreas indígenas, em 1973, era a de serrarias nas reservas localizadas na região sul nos seguintes postos indígenas: Guarapuava, Palmas e Apucarana no Paraná, Xapecó em Santa Catarina, Nonoai e Guarita no Rio Grande do Sul.

\subsection{Extrativismo Vegetal}

Esta atividade era representada pela coleta de castanha do Brasil, no Pará, e pela extração de palmito, no posto Indígena Porto Lindo, Mato Grosso do Sul.

Para 1973 estavam previstos projetos de coleta de castanha nos postos indígenas Mãe Maria, Pucuruí, Parakanan, Gorotire, Kubenkrankein, Krokraimoro, Bau, Sororó e Cateté.

A FUNAI justifica a implantação desses projetos para

Evitar a comercialização entre o Índio e o regatão em condições desvantajosas para os indígenas. Nessa transação o Índio adquire por preços exorbitantes os bens de consumo e entrega sua produção por preços vergonhosamente 
aviltados. Através dos projetos da FUNAI são fornecidos aos Índios, a preço de custo, tudo que ele necessita e sua produção é adquirida a preço superior ao corrente na região. Com isso, evitam-se a exploração do Índio e o contato com elementos inescrupulosos. (FUNAI, 1973, p. 64).

O que a FUNAI não explicita nesse plano é que a produção ficava retida no Departamento Geral do Patrimônio Indígena (DGPI), e que os indígenas que coletavam a castanha, assim como em outros projetos, eram utilizados como mera mão de obra.

O economista Sergio Pery Gomes, então diretor do DGPI, cita a palavra "emancipação" em 1973, relacionada aos projetos de desenvolvimento e à demarcação das terras indígenas. Como se observou, em 1973, já estavam firmemente delineadas as diretrizes da política indigenista oficial para o futuro breve, em especial no que se refere à execução e à implementação de projetos de desenvolvimento comunitário. Também foi nessa fase que se deu maior atenção a monitores indígenas de ensino bilíngue, que se pretendia caminhasse pari-passu com a formação de monitores agrícolas.

\section{O PROJETO DE EMANCIPAÇÃO E OS PROJETOS DE DESENVOLVIMENTO COMUNITÁRIO}

Em 1974, o General Ismarth de Oliveira, presidente da FUNAI, afirmou que:

É necessária uma completa reformulação dos planos feitos para os grupos tribais [...]; é preciso dar a esses projetos uma feição sócio-econômica que motive a comunidade tribal para uma futura integração. (JORNAL DO BRASIL, 1974 apud SILVA, 1982, p. 81).

Apesar da afirmação de que é necessária uma completa reformulação da política indigenista, quase nada foi alterado, e continuaram as diretrizes para a demarcação de terras, e principalmente os esforços para a integração dos povos indígenas.

Em 1976, no Informativo FUNAI (ano 5, junho de 1976), aparece sob o título de "Nova Filosofia", o seguinte texto:

[....] A FUNAI pretende dar condições à comunidade indígena para participar da economia regional através de projetos comunitários agrícolas ou pecuários para subsistência do grupo e comercialização dos excedentes e capacitar o 
índio, ao mesmo tempo, a assumir a responsabilidade de execução dos próprios projetos, através dos conhecimentos adquiridos. (FUNAI, 1976, p. 62).

A novidade desse pronunciamento foi a criação de equipes volantes agrícolas e de um grupo multidisciplinar visando a aplicação da nova filosofia do órgão (FUNAI, 1976).

Em 1977 existiam trinta e três projetos de desenvolvimento e de subsistência em andamento, com um investimento de $\mathrm{Cr} \$ 14$ milhões para a implementação de roças de trigo, soja e feijão e para o desenvolvimento da pecuária, de acordo com notícia do jornal a Folha de São Paulo, no dia 21 de junho de 1977 (apud SILVA, 1982, p. 82). Pode-se observar que não houve um crescimento expressivo na expansão dos projetos em relação a 1973, época em que perfaziam um total de vinte e quatro, incluindo os projetos de coleta de castanha.

Em finais de 1976, é importante ressaltar, vieram a público os propósitos do Ministério do Interior, sob a administração do ministro Rangel Reis, com o "Projeto de Emancipação". Em dezembro de 1976, Rangel Reis fez um pronunciamento oficial que causou grande impacto na opinião pública: afirmava ele que, em de vinte anos, todos os grupos indígenas estariam emancipados através de uma "emancipação progressiva", e mencionava várias "comunidades" do Rio Grande do Sul, aquelas mesmas que sofriam projetos econômicos em suas terras, conforme mencionado acima.

No dizer de Rangel Reis (1977): “A imagem que se faz de que o índio é indolente é errada; o índio produz e pode produzir e pode ser um cidadão mais útil ao seu país, sem prejuízo de seus hábitos e de sua cultura" (FOLHA DE SÃO PAULO, 1977 apud SILVA, 1982, p. 82).

Em novembro de 1978 foi entregue à imprensa uma minuta do Projeto de Emancipação, quando foi criada uma comissão que

Parágrafo 1 - promoverá a elaboração e a execução de um plano integrado de ação de desenvolvimento das comunidades indígenas, a ser desdobrado com medidas de médio e longo prazos, para permitir maior assistência técnica, econômica e social àquelas comunidades e aos silvícolas, visando a incorporá-los gradativamente à comunhão nacional, mediante a integração ou à emancipação de forma a assegurar-Ihes o pleno direito de seus direitos civis. (O ESTADO DE SÃO PAULO, 1978 apud SILVA, 1982, p. 83). 
Em finais de novembro o ministro Rangel Reis respondeu a uma crítica publicada no jornal o Estado de São Paulo, sobre o projeto de emancipação dos povos indígenas brasileiros, com os seguintes termos:

O que se busca na realidade, com toda a sinceridade de propósitos, é preparar as comunidades indígenas ou o índio isolado, levando em conta os diferentes graus de aculturação, para este convívio com a sociedade [...] e sem qualquer prazo marcado, proporcionar aos índios as oportunidades que a nação brasileira oferece aos seus filhos e torna-los mais participantes da vida nacional. (O ESTADO DE SÃO PAULO, 1978 apud SILVA, 1982, p. 83).

Após o fracasso do Projeto de Emancipação, em 1979, devido à grande resistência de setores organizados da sociedade civil, com antropólogos, Igreja Católica e mesmo funcionários da FUNAI, os projetos de desenvolvimento comunitário ganharam força e começaram a ser aplicados extensivamente sem serem alvo de críticas por parte dos setores comprometidos com a causa indígena. De uma forma geral, foram até bem recebidos. De certa forma, esses projetos eram pensados como a salvação das comunidades indígenas, a solução para o "problema indígena".

Na verdade, esses projetos constituem uma alternativa aceitável perante a opinião pública, mas mantém os objetivos do Projeto de Emancipação, embora revestidos de uma forma menos agressiva e menos explicitada.

Em julho de 1979 a FUNAI declarou à imprensa que pretende tornar autossuficientes, até o ano de 1985, todas as comunidades indígenas das regiões Nordeste, Centro-Oeste e algumas do Sul e do Norte do país, através de programas de desenvolvimento comunitário. Ainda a "integração" à sociedade deverá, de acordo com esse pronunciamento, ser conduzida de forma gradual e harmônica, segundo o estágio de aculturação das diversas comunidades, e, paradoxalmente, prega "[...] o respeito à sua cultura, tradição, costumes e patrimônio" (O ESTADO DE SÃO PAULO, 1979 apud SILVA, 1982, p. 84).

Durante o ano de 1979, a FUNAI anunciou que estava desenvolvendo 55 projetos agrícolas (contra dez em 1973) em todo o território nacional, abrangendo uma área de 11.943 hectares, com plantações de arroz, soja, milho e café, "entre outros produtos". Foram investidos neste período Cr\$97.758.000,00.

Nesta diretriz política de promover a integração, em 1980 já havia 132 projetos em execução e a FUNAI e o Ministério de Interior esperavam colher 34 mil 
toneladas de arroz, feijão, soja e mandioca. O ano de 1980 foi considerado pelo órgão assistencial como o ano de consolidação dos projetos de desenvolvimento comunitário, com recursos aplicados na ordem de Cr\$334.215.000,00 (DIÁRIO DE CUIABÁ, 1981 apud SILVA, 1982, p. 83).

O café, amendoim, trigo, cebola, castanha, caju e a cana de açúcar, somam-se à lista dos produtos explorados pelos projetos de desenvolvimento em áreas indígenas. Em 1980, ainda havia a expectativa de uma produção de oito toneladas de peixes, provenientes do Parque Araguaia, e 13.608 quilos de casulos produzidos pelos Terena e Guarani do posto indígena Araribá (DIÁRIO DE CUIABÁ, 1981 apud SILVA, 1982, p. 83).

Em 1981, a FUNAl informou que implementaria uma

Nova orientação em sua política de ação, com vistas a maior desenvolvimento social das comunidades indígenas por meio de melhor ajuste às suas realidades específicas [...]. (O ESTADO DE SÃO PAULO, 1981 apud SILVA, 1982, p. 84).

Sobre a produção dentro das reservas, aconselha-se maior participação dos indígenas, assim como a renda obtida na produção em favor da comunidade produtiva com fins à sua emancipação econômica. Essa chamada "nova orientação" também diz respeito à assistência médica e educacional.

Quadro 1-Quadro geral do crescimento dos projetos e investimentos:

\begin{tabular}{|c|c|c|c|}
\hline Ano & $\mathbf{N}^{\text {o. }}$ de projetos & Investimento & Área \\
\hline 1973 & 24 & Sem informação & Sem informação \\
\hline 1976 & $?$ & $\operatorname{Cr} \$ 549.000,00$ & Sem informação \\
\hline 1977 & 31 & $\operatorname{Cr} \$ 22.000 .000,00$ & Sem informação \\
\hline 1978 & Sem informação & $\operatorname{Cr} \$ 98.659 .000,00$ & 11.943 hectares \\
\hline 1980 & 132 & $\operatorname{Cr} \$ 334.215 .000,00$ & Sem informação \\
\hline 1981 & 156 & $\operatorname{Cr} \$ 2.595 .000 .000,00$ & Sem informação \\
\hline
\end{tabular}

Fonte: Joana A. Fernandes Silva (1982, p. 85).

\section{OS PROJETOS E SUA LEGITIMAÇÃO}

Geralmente as relações econômicas dos indígenas com a população abrangente são estabelecidas através da venda temporária de sua força de trabalho, ou então da venda de sua produção agrícola ou artesanal. Essas relações são bastante problemáticas, pois propiciam uma super exploração do trabalho indígena. No 
que se refere ao trabalho remunerado, os salários pagos são sempre inferiores aos pagos aos não indígenas que desempenham as mesmas funções. Além disso, algumas vezes eles precisam afastar-se de suas casas por períodos prolongados e abandonam temporariamente suas roças de subsistência, o que traz consequências na relativa estabilidade socioeconômica para as famílias do trabalhador e nas aldeias.

O que justifica a execução de projetos de desenvolvimento em comunidades indígenas era a alegação de que os povos indígenas são explorados ao venderem sua força de trabalho. A FUNAI, neste período, tornou-se uma espécie de intermediária entre o produtor indígena e o sistema econômico capitalista, apropriando-se do produto do trabalho indígena, realizado nas terras indígenas apropriando-se e manipulando esse resultado. Pode-se entender que, de uma certa maneira, o órgão assistencial assumiu o papel de patrão.

Os projetos de desenvolvimento comunitário não foram outra coisa que um plano econômico para forçar a integração dos povos indígenas ao mercado capitalista e à sociedade nacional e uma busca de modificar seu comportamento e sua ideologia econômica.

A política de implementação de projetos de desenvolvimento comunitário buscou sua legitimidade na afirmação de que, em tese, possibilitariam a independência do trabalho remunerado contratado por fazendeiros e regionais. Mas, foram uma forte pressão no sentido de direcionar os povos indígenas afetados por essa política a uma nova racionalidade econômica. Essa nova racionalidade visava a inserção desses povos ao sistema capitalista, a ocupação intensiva de suas terras, o abandono de seu modo de produção, a manipulação de dinheiro e participação na sociedade de consumo.

Na discussão do modo de produção doméstico, Claude Meillassoux (1977) afirma que o sistema de produção capitalista tende a negar todos os outros sistemas de produção, mas permitindo a coexistência de formas marginais, utilizando-se destas na medida em que lhe convém, como por exemplo, nas sociedades coloniais, ou destruindo-as. Nesta lógica, a partir do momento em que os povos indígenas deixam de interessar ao sistema capitalista como reserva de mão de obra, ou passam a ser considerados um obstáculo por ocuparem terras desejadas, dispositivos são criados visando sua eliminação. 
O momento limite que o capitalismo permite a sobrevivência de formas econômicas não capitalistas parece ser aquele em que os agentes dessas formas se transformam em quistos, impedindo seu avanço. A consideração de que as terras indígenas não são bem aproveitas é um dos elementos fundamentais que provocam a visão de que são obstáculos ao avanço do desenvolvimento e do "progresso".

Este não é um fato novo. A laboriosidade dos indígenas é discutida desde os primeiros contatos com os portugueses. Este foi o grande argumento para legitimar a exploração, dominação, e mesmo o extermínio. O fato de dependerem da caça e da pesca para sua alimentação contribuiu muito para essa visão do colonizador, uma vez que essas são atividades de lazer para o "branco civilizado".

Assim, os projetos de desenvolvimento comunitário aparentemente viriam utilizar uma mão de obra indígena percebida como desocupada, dispersa no trabalho em fazendas e, ao mesmo tempo, contribuiriam para dar uma utilidade às terras consideradas improdutivas. O fato desses projetos serem executados entre povos considerados "aculturados" e com contato intenso com a sociedade abrangente não é fortuito. Esses povos são aqueles que estão localizados nas regiões de avançado grau de implantação do sistema capitalista, como Mato Grosso do Sul, Bahia, Rio Grande do Sul e etc. As populações indígenas desta região são consideradas economicamente improdutivas e como entraves à sanha da ocupação selvagem de terras no Brasil.

\section{OS PROJETOS DE DESENVOLVIMENTO NO SUDOESTE DE MATO GROSSO DO SUL}

É importante relembrar que há dois tipos de projetos de produção aplicados em terras indígenas: os projetos de subsistência e os projetos econômicos, cuja natureza são muito distintos.

Os projetos de subsistência tinham como objetivo auxiliar na produção de alimentos para promover uma segurança alimentar nas precárias condições dos Guarani-Kaiowá em Mato Grosso do Sul; eram idealizados e aplicados por antropólogos ou missionários, mas também a FUNAI realizou alguns desses projetos.

Os projetos econômicos, implementados pelo órgão indigenista, dentro de uma política de integração, visavam a produção para o mercado, conforme se demonstrou acima. 
Nesta região, as onze reservas indígenas ${ }^{3}$ foram alvos dessa política, mas em algumas delas, havia projetos econômicos e de subsistência sendo realizados simultaneamente. No período estudado, entre 1976 e 1980, apenas a Aldeia de Campestre não tinha projetos de nenhuma natureza. Campestre é que tinha as piores condições, pela exiguidade da terra, com apenas dois hectares, e seus moradores sobreviviam trabalhando nas fazendas dos arredores.

Todos os projetos do período eram agrícolas, com exceção de Jacareí, onde além da agricultura se extraía erva-mate. A FUNAI privilegiava o cultivo da soja, do milho e do feijão.

Existe um certo consenso entre os antropólogos, missionários e funcionários da FUNAI de que a integração é inevitável, uma questão de tempo. A igreja e os antropólogos demonstravam maior preocupação com o processo e com a preparação dos Guarani da região para a integração. A FUNAl tinha os olhos voltados para a integração, como um fim em si mesma.

Havia também uma concepção de que os povos indígenas não são totalmente capazes de produzir para sua própria sobrevivência. A preocupação com a exploração do trabalho remunerado e com a changa, era comum, uma vez que os Guarani eram muito explorados, nada respeitados e até recebiam alimentação estragada durante o período de trabalho nas fazendas.

Os projetos executados pela FUNAI, de ideologia desenvolvimentista, tinham não apenas o objetivo de ocupar intensivamente as poucas terras disponíveis para os Guarani, mas também o de obter uma produção comercializável e, em tese, lucrativa. Grande ênfase era dada ao uso de tecnologias, através de tratores e máquinas agrícolas 4 .

Os projetos da igreja, mais especificamente da Católica, eram os de subsistência, embora se almejasse a obtenção de algum excedente para ser comercializado. Em Mato Grosso do Sul, o grupo atuante procurava introduzir o mínimo de alterações tecnológicas e demonstrava muito respeito à cultura dos Guarani

3 Eram elas Posto Indígena (PI) Benjamin Constant ou Amambai, Campestre, Jacareí ou Porto Lindo, Jacaré, subordinada ao PI Benjamin Constant, Jacaré, Guembe, Posto Indígena Panambi (Lagoa Rica e Panambizinho), Limão Verde, Posto Indígena Takuapiru, Posto Indígena Pirajuí, Posto Indígena Nicolau Horta, Pirakoá, Posto Indígena Ramada, ou Sassoró.

4 Nada parecido ao que se viu mais tarde em termos de colheitadeiras gigantes nas agropecuárias, que controlam a produção e produtividade com sofisticados meios digitais. 
e dos Kaiowá. Adeptos da Teologia da Libertação, outras preocupações acompanhavam as de ordem econômica e alimentar; existia a intenção de "conscientizar", sem praticar o proselitismo religioso, sobre o que tenho alguma dúvida. Além das preocupações com a produção de alimentos, havia uma política em torno das lideranças consideradas tradicionais, ao contrário da FUNAI que buscava apoiar-se naqueles que falavam melhor o português e que, em geral, eram um tanto marginais à lógica do cotidiano e das políticas internas nas aldeias.

Os projetos executados por antropólogos ${ }^{5}$ tinham também a proposta da subsistência e também pregavam o respeito. Os antropólogos não davam ênfase à alteração tecnológica, mas as roças eram organizadas de uma maneira mais próxima a do sistema capitalista, do que com as tradicionais roças de toco praticadas pelos Kaiowá.

Embora existam diferenças marcantes entre as três linhas de trabalho, todas explicitavam uma fé de que estavam retomando e recuperando um princípio da organização tradicional dos Guarani, o modo de produção comunitário. A maior parte dos trabalhos agrícolas eram realizados através de mutirão, e se supunha que antes do contato com os colonizadores, os Guarani organizavam suas atividades econômicas através dos mutirões. Havia um desconhecimento de que a produção de alimentos era organizada pelas famílias nucleares e que os mutirões eram acionados em oportunidades que demandavam mais pessoas, tais como desmatamentos e preparo da terra. As três linhas de atuação se equivocavam também no que dizia respeito à organização do trabalho: apenas os homens eram chamados para as roças comunitárias. Havia também um desconhecimento de que o trabalho de manutenção das roças era basicamente feminino.

Gostaria também de lembrar as missões protestantes nesta região de Mato Grosso do Sul, presentes em todas as aldeias Guarani. As missões protestantes não se envolviam com os trabalhos de produção de alimentos, mas limitavam-se a um rígido proselitismo religioso, com a assistência médica e educacional. Eram missões extremamente conservadoras, não se envolviam com reivindicações políticas dos Guarani Kaiowá. Para eles, o importante era salvar as almas do inferno e do castigo eterno, mantendo seu almejado "rebanho" em saúde relativa para

5 Aqui relembro o grupo dos saudosos Rubinho Almeida e do Celso Aoki (conhecido como Japonês), ambos intensamente envolvidos e dedicados aos Kaiowá. 
que pudessem frequentar os cultos religiosos. A "Missão alemã" chegou a fazer forte oposição dos antropólogos no Posto Pirajuí. Nessa época, eu pensava que o trabalho na educação escolar das crianças tinha como objetivo ensiná-las para poderem ler a bíblia.

\section{A NOÇÃO DE MELHORAR: “CIVILIZAR” PARA MELHOR DOMINAR}

A tentativa de subordinação e integração do índio brasileiro não é recente: ela existe e é buscada desde que o primeiro português pisou o litoral brasileiro. A "civilização" europeia foi o parâmetro que direcionou todo o contato e toda a política indigenista através dos séculos.

Tampouco mudaram os métodos de atração, embora suas características variem de acordo com as conjunturas políticas e econômicas momentâneas. É justamente a impulsão de "civilizar", sempre de acordo com o modelo europeu, em total desconsideração às características das sociedades indígenas, justificou ideologicamente a dominação.

Representantes da Igreja (jesuítas, dominicanos, capuchinhos e etc.) bandeirantes, garimpeiros, indigenistas do SPI e da FUNAI, todos foram unânimes na determinação: é necessário civilizar, integrar.

Representantes da Igreja (jesuítas, dominicanos, capuchinhos, por exemplo), bandeirantes, garimpeiros, membros dos órgãos indigenistas, todos foram unânimes: é necessário civilizar, integrar.

Porém, dizer que, fundamentalmente, não mudaram os métodos de atração é dizer pouco; se antes tentava-se atrair populações indígenas com espelhinhos, atualmente jogam-se tratores e colhedeiras mecânicas como atrativo.

É necessário constatar três aspectos: a política indigenista oficial e seus conteúdos filosóficos, a política atualizada em uma prática e, finalmente, as ações desvinculadas da política protecionista oficial.

Não podemos esquecer que a maior parte dos processos de contato ocorreram violentamente. Após o lema do General Rondon, "morrer se preciso for, matar nunca", houve uma suavização dos métodos de atração. A imposição do modo de produção capitalista e da cobiça pelas terras indígenas nunca se deram de boas maneiras e custaram o extermínio da maior parte dos povos indígenas brasileiros. 
O Serviço de Proteção foi fundado em 1910, após um movimento de reação a um artigo de Hermann Von Hering, diretor do Museu Paulista, que defendeu o extermínio completo de "[...] índios arredios e hostis ao processo de colonização" (apud RIBEIRO, 1977, p. 129-36). O pronunciamento e o ponto de vista de Von Hering era apenas a expressão de um ponto de vista compartilhado pela população brasileira, que percebia a existência dos povos indígenas como um obstáculo aos propósitos de ocupação do território nacional.

A constatação de que a atuação de missões religiosas para pacificação e integração dos povos indígenas brasileiros, no século XIX e anteriores, havia sido um fracasso devido a um forte etnocentrismo e à pouca compreensão que estas demonstravam em relação aos seus prosélitos, provocam maior resistência à aceitação dos valores da sociedade abrangente. Não foram raros muitos massacres de missionários, como por exemplo o da missão de Itambacury, no Vale do Rio Mucuri e Doce. Ao lado de uma crise ampla da Igreja, a inoperância da ação missionária como arrebanhadora dessas populações, foram fatores que pesaram na decisão do Estado em criar um órgão específico e centralizado para tratar com os povos indígenas. Apesar do controle do Estado sobre assuntos indígenas, foi garantida amplamente a liberdade de catequese a todos os credos religiosos. Até os dias atuais há uma certa divisão de trabalho entre a Igreja e o órgão tutelar, como também existem aldeias que estão sob o controle de uma missão, sem a presença da FUNAI.

É importante não perder de vista os princípios filosóficos que nortearam a implantação do Serviço de Proteção ao Indio, na medida em que a orientação atual da FUNAI está diretamente relacionada com essa filosofia. Aqui talvez possam ser encontradas as sementes da política de implantação dos projetos de desenvolvimento comunitário. O positivismo de Augusto Comte orientou os princípios filosóficos quando da criação do SPI. Baseado no princípio humanista, o SPI propunha-se a lutar pela autonomia das sociedades indígenas brasileiras, na certeza de que uma vez libertas das pressões externas, evoluiriam espontaneamente. Darcy Ribeiro (1977, p. 139) comentou que, nesse sentido, o SPI imaginava que "[...] os índios eram capazes de progredir espiritualmente e para tal, era necessário propor-lhe meios".

No entanto, o SPI, com estes princípios trazia inerente à sua política, uma ação de negação dos povos indígenas. O órgão protetor empenhou-se em tanto 
em pacificar grupos "hostis" com os quais as frentes de expansão da sociedade nacional entravam em conflito, como em modificar a cultura de povos indígenas já em contato, através de incentivos econômicos.

O Serviço não procura, nem espera transformar o índio, ou seus hábitos, os seus costumes, a mentalidade, por uma série de lições verbais, de prescrições, de conselhos; conta apenas melhorá-lo, proporcionando-lhe os meios, os exemplos e os incentivos indiretos para isso: melhorar seus meios de trabalho pela introdução de ferramentas; as suas roupas, pelo fornecimento de tecidos e máquinas [...] E de todo esse trabalho resulta que o índio torna-se um melhor índio, e não um mísero ente sem classificação social possível, por ter perdido a civilização a que pertencia sem ter conseguido entrar naquela para onde o queriam levar (NICOLAU HORTA BARBOSA apud RIBEIRO, 1977, p. 141).

Esse discurso de Horta Barbosa parece ser uma redefinição de estratégias por parte do SPI, cujo programa previa a rápida transformação dos indígenas em lavradores. Essa previsão decorre claramente da influência do positivismo, para o qual o homem é passível de progresso, desde que lhe sejam das as condições para que se desenvolva.

Assim, de acordo com o ponto de vista de Rondon (apud RIBEIRO, 1977, p. 191-2), "[...] o atraso dos índios não decorria de sua propalada incapacidade congênita, mas da exploração e do tratamento desumano a que eram submetidos desde a descoberta". O próprio Darcy Ribeiro, defensor do SPI, admitiu que o órgão não previu como entrave de suas intenções, a própria resistência cultural indígena (RIBEIRO, 1977).

Essa redefinição de estratégias é condensada em uma frase de Nicolau Horta Barbosa (apud RIBEIRO, 1977) “[...] não incorporar párias, mas fazer do índio, um índio melhor", devendo o SPI conduzir o processo de sua integração progressiva na vida regional. "Fazer do índio, um índio melhor", segundo Darcy Ribeiro (1977, p. 192) significava dar-Ihe condições e atrativos para a integração, através da introdução de ferramentas e outros itens da sociedade capitalista. Paralelamente à introdução de elementos estranhos à cultura indígena, houve a implantação de projetos econômicos que muito beneficiaram o SPI, pois os lucros do trabalho indígena eram administrados e utilizados pelo órgão indigenista.

De acordo com Ribeiro (1977, p. 210): “Enganaram-se ao supor que, fazendo um Posto Indígena proprietário de um rebanho de alguns milhares de cabeça de 
gado, suficientes para tornar rico a um particular, assegurariam a emancipação econômica dos Índios".

Não apenas a pecuária foi utilizada como recurso para forçar a integração, mas também as atividades agrícolas e extrativas. Durante a gestão do SPI, o trabalho indígena foi frequentemente utilizado a serviço do órgão protecionista.

O SPI teve momentos de atividades intensas, seguidas por períodos de certo marasmo, mais ou menos de acordo com momentos políticos que o país passou. Nos primeiros anos após sua fundação "pacificou" quase todos os grupos indígenas hostis que se interpunham ao avanço das frentes pioneiras nacionais. Como um balanço do que ficou das atividades do SPI, pode-se concluir que serviu muito mais à sociedade nacional do que aos povos que deveria proteger. Pacificações e delimitação de territórios que aparentemente protege e defende, é uma liberação de terras para os não indígenas que estão se instalando nos territórios ocupados por indígenas. Por suposto, as delimitações jamais são da área ocupada pelos povos indígenas, mas de parcelas, geralmente mínimas e insignificantes.

Retomando a discussão sobre os projetos econômicos do SPI, é possível encontrar algumas correlações bastante claras entre a política indigenista anterior a 1967 e posteriormente, com a criação da FUNAI.

Roberto Cardoso de Oliveira (1972), ao comentar os projetos desenvolvidos durante a gestão do SPI, refere-se à mentalidade empresarial desse órgão, que para ele

Representa o estabelecimento de uma orientação totalmente voltada para a transformação dos Postos Indígenas (unidades de base do SPI) em verdadeiras empresas voltadas à produção e ao lucro. A concepção inerente a essa orientação é a de que o índio só pode "civilizar-se" pelo trabalho, mas ao trabalho induzido, que lhe é ensinado pelo civilizado. (OLIVEIRA, 1972, p. 74).

Completando o pensamento do autor sobre a orientação da política indigenista neste momento, parece ser importante a sua constatação de dois aspectos determinantes: o primeiro é o pressuposto de que "[...] a redenção do Índio somente pode se alcançada pelo trabalho", e que o "trabalho para eles (burocratas do SPI), ao que tudo indica, é a atividade regular na produção de bens passíveis de interesse comercial na sociedade brasileira" (OLIVEIRA, 1972, p. 74). 
Essa concepção do que é trabalho parece ser um dos fatores de maior peso na organização dos projetos de desenvolvimento. O conceito de trabalho, unicamente sob a ótica do capitalismo, que nega as atividades de subsistência enquanto tais, na medida em que não geram lucro, caminha ao lado da ênfase dada à técnica, tanto durante o SPI, como atualmente pela FUNAI. A diferença é que para o primeiro, a técnica estava mais relacionada à postura positivista, enquanto que para a FUNAl é mais uma questão de imposição, é expressão do aceleramento de uma política de integração, levemente mascarada com um discurso protecionista.

Dentro desse sistema de trabalho e coerção para que o indígena trabalhe, muitas vezes com técnicas sofisticadíssimas na agricultura, paralelamente ao uso de técnicas tradicionais das roças familiais, surge uma figura de singular importância: o chefe do posto indígena. Essa figura que antes da grande força dada aos projetos de emancipação econômica, cumpria outras funções, tais como a defesa das terras indígenas, intermediação de conflitos entre indígenas e não indígenas, agenciador de empregos, ganha importância e começa a assemelhar-se a um capataz de fazenda.

O chefe do posto indígena tem cumprido uma função estratégica no andamento dos projetos que são idealizados em Brasília e que já vem com um programa e um cronograma a cumprir. Nesta posição, depende dele o bom desempenho das comunidades escolhidas para os projetos nas roças coletivas, da manipulação da comunidade em momentos de crise que possam interferir no bom andamento do trabalho e etc.

Roberto Cardoso de Oliveira (1972) definiu a posição do chefe de posto indígena durante a gestão SPI como de patrão, e caracterizou as relações entre índios e funcionários do órgão tutelas como relações de patrão-empregado. Parece-me que, em certa medida, ele não explicitou completamente a complexidade dessa relação, composta por uma tríade: Assessoria de Planejamento (ASPLAN), de onde emanam os projetos e as ordens, chefe do posto e o indígena a quem se determina a obediência e adesão às propostas.

Neste contexto o chefe de Posto era um intermediário dos interesses da cúpula administrativa da FUNAI: as decisões quanto ao produto, área a ser plantada e produção esperada, partem dos altos escalões burocráticos da FUNAI. O chefe 
de posto recebe o planejamento das atividades já pronto e sem ser consultado, deve orientar e cooptar os indígenas para trabalharem nas roças ${ }^{6}$.

Em outros termos, as decisões partem de cima para baixo, coerentemente com o entendimento da FUNAI que toma os indígenas como absolutamente incapazes, apesar de ser considerado "relativamente capaz" pelo Estatuto do Índio, criado em 1973. Eles são considerados incapazes até de produzirem sua própria alimentação. Isso, claro, na visão ideológica do órgão indigenista, senão como se justificaria tanta invasão no sistema de vida desses povos?

Assim como o indígena engajado nos trabalhos das roças coletivas não participa das decisões a respeito do que fazer, e tampouco tem acesso ao resultado do produto de seu trabalho. As vendas são realizadas pela FUNAI, da maneira como entende que deva ser feita. Esse procedimento não apresenta novidades em relação ao extinto SPI, apenas com um detalhe: neste, a produção era arrebatada das aldeias e a renda auferida era contabilizada como "renda indígena" canalizada dos postos indígenas às inspetorias regionais e destas, para a diretoria central em Brasília, conforme Oliveira (1972). Esta renda indígena, teoricamente, era redistribuída entre os postos indígenas, independentemente da contribuição específica de cada povo ou aldeia, traduzindo uma tentativa de autofinanciamento do SPI.

Para a FUNAI, os lucros devem ficar retidos nas unidades produtoras com o objetivo e cobrir gastos anteriores, comprar sementes e repor materiais utilizados. Neste caso, o propósito é que os postos indígenas se autofinanciem. A este autofinanciamento dos postos indígenas, que deveriam ser transformados em lucrativas empresas, é o que a FUNAI chama de "autossuficiência" dos povos indígenas.

Contrapondo-se à poética e ultrapassada posição de certos sonhadores que vislumbraram as comunidades indígenas como eternos "oásis humanos", intocados pela sociedade envolvente, a Fundação Nacional do Índio busca, com projetos racionais e ajustados às diferentes realidades de cada grupo, respaldar estas comunidades para a espontânea projeção econômica, na exata medida que se processa a integração. (FUNAl, 1981, n.p.).

${ }_{6}$ Deve ser ressalvado que em alguns casos, o pré-projeto é feito pelo chefe de Posto, como é o caso de Panambi. 
Os Guarani, tidos como integrados desde o ano de 1900 (RIBEIRO, 1977), constituíram-se em um dos alvos prediletos de FUNAI para a execução de projetos de desenvolvimento comunitário. A ideia de que já estavam muito integrados à vida e economia regionais forneceu a visão de que a aplicação de projetos encontraria ressonância entre essas comunidades, bastando para tal, apenas um pequeno impulso e introdução de tecnologia para que se integrassem definitivamente à sociedade nacional.

Contudo, apesar do empenho do órgão tutelar, estes projetos não têm sido muito bem-sucedidos. Para a compreensão da pouca receptividade que estes projetos têm encontrado entre os grupos envolvidos é necessário fazer uma descrição de seus métodos, objetivo e justificativas, bem como aspectos da organização e ideologia dessas sociedades.

É importante lembrar de que, apesar dos Guarani serem uma das nações indígenas mais numerosas atualmente no Brasil, sobrevivem em território exíguo, descontinuo e em aldeias muito pequenas. Seu território diminuiu drasticamente a partir do ciclo da erva-mate e hoje é recortado por cidades e fazendas, o que impõe maior isolamento entre os vários grupos e subgrupos.

Em contraposição à proposta simples e imediatista de trabalho em troca de alimentação existe, subjacente aos projetos, uma mais complexa, planejada para longo prazo. No texto dos projetos de desenvolvimento comunitários, os cálculos vêm acompanhados de um texto com justificativas e objetivos. Os objetivos almejados na implantação dos projetos não são muito variados. Em geral, os textos vêm com os seguintes termos:

Promover a melhoria das condições socioeconômicas da comunidade " $x$ " visando sua integração gradativa e harmoniosa à sociedade nacional, e Propiciar assistência integrada (financeira, técnica e administrativa), no sentido de estimular por meios compatíveis com o estágio de aculturação da mencionada comunidade, a implantação de lavoura de subsistência e exploração mecânica. (FUNAI, 1982, n.p.).

A preocupação com a integração de grupos indígenas à sociedade nacional e utilização de recursos considerados úteis para promovê-la é uma constante por parte da FUNAI.

De alguns anos para cá, muito cautelosamente, a FUNAI vem fazendo uma certa propaganda na imprensa e em seu Boletim Informativo, sempre apresentando 
dados ufanistas sobre os resultados obtidos pelos projetos, assim como de seus investimentos. Na promoção desta sua política, a FUNAI não esclarece a quem estes projetos estão beneficiando e tampouco qual o destino dado à produção gerada pelo trabalho indígena.

Como se justifica a implantação desses projetos? Qual o discurso da FUNAI no sentido de legitimar usa intenção de interferir na economia dos povos indígenas?

Textualmente a justificativa é essa, como se pode encontrar no texto do Projeto de Desenvolvimento Integrado de Panambi, e Projetos elaborados Safra de 1979/80 (FUNAI, 1980).

As comunidades indígenas brasileiras em adiantado estágio de aculturação, normalmente transacionam com a sociedade envolvente os produtos de suas lavouras. Na maioria das vezes, por força da pequena quantidade e má qualidade da produção oferecida, os rendimentos auferidos pelos indígenas não são compatíveis com suas necessidades e nem com o esforço despendido. Como alternativa, alugam sua força de trabalho nas fazendas o que agrava o problema e os torna dependentes de seus vizinhos civilizados [sic] (FUNAI, 1980).

Novamente se explicita a questão da integração e os parâmetros pelos quais a FUNAI propõe o desenvolvimento de lavouras em comunidades em "adiantado estado de aculturação". O aspecto mencionado da produção indígena sempre mão remunerado é um dos argumentos que o órgão tutelar sempre recorre para legitimar os projetos. É comum acontecer em aldeias que estabelecem contato bastante intenso com os regionais, um certo círculo vicioso no que diz respeito à produção interna de alimentos. Estes grupos normalmente têm uma história mais ou menos recente de contato, de perda de terras e de desarticulação social. Ainda pode ocorrer que, na atualidade, as pequenas porções de terra que conseguiram salvar da invasão de neobrasileiros estarem sendo ameaçadas de completa espoliação. Isto provoca grande insegurança devido à ameaça sempre presente de serem definitivamente expulsos. Em consequência, não investem muito trabalho no interior de suas terras e a parcela de mão de obra ativa é impulsionada a procurar trabalho em fazendas, seringais e etc. ocorre que a maior demanda para trabalhos agrícolas em fazendas coincide com o período de plantio dos gêneros que assegurariam a subsistência do grupo. No entanto, como não têm alimentos armazenados, necessitam lançar mão ao trabalho assalariado para cobrir parte de suas necessidades básicas. 
Por esse processo forma-se um círculo que dificilmente pode ser rompido, aliado ao fato das novas necessidades que inegavelmente surgem após o contato, as quais somente podem ser satisfeitas através do pagamento que recebem pelo seu trabalho em fazendas.

Mas, deve ser esclarecido que, se um grupo tem condições mínimas de disponibilidade de terra e não está sofrendo uma epidemia, ele vai fazer roças. Desta maneira, o trabalho assalariado é um recurso que se destina à complementação da produção interna e meio de acesso a certos bens manufaturados, como por exemplo, roupa e remédios.

Quero enfatizar novamente, a lavoura somente é abandonada em situações de crise muito grave. Caso contrário, sempre se cultivam gêneros da dieta tradicional, mesmo que não sejam suficientes para cobrir todas as necessidades de subsistência.

\section{ALGUMAS PALAVRAS FINAIS}

No período da pesquisa de campo pude observar que os Kaiowá de Panambi não se interpunham frontalmente aos comandos da FUNAI, personalizados na figura do chefe de posto. A resistência que eles interpuseram aos propósitos assimilacionistas era silenciosa e se expressava no não comparecimento às reuniões, na falta para os trabalhos e à chamada para pulverizar a soja com inseticida, o que resultou em uma perda quase total dos grãos. Eles não discutiam, não brigavam, silenciavam simplesmente. Essa resistência deve ter ocorrido com outros povos indígenas a quem se tentou submeter aos projetos de desenvolvimento do órgão tutelar.

Refletindo agora, percebo a quão penosa deve ter sido a posição dos chefes de posto, pois a eles também foi imposto um trabalho intenso e sobre eles foi jogada a responsabilidade de cumprir uma missão que tampouco tinha a ver com eles. E como eles poderiam contornar uma resistência com a força dos Kaiowá, silenciosa e insubmissa?

Já se passaram praticamente 40 anos dessa minha convivência com os Kaiowá de Panambi, que deixaram uma marca indelével, tanto em minha formação profissional, como em termos de afetos profundos por um povo.

Infelizmente, percebo que as pressões sobre eles nunca amainaram, ao contrário, se intensificaram. Há notícias cotidianas de violência e de tentativas de 
expulsão das poucas terras que o SPI reservou a eles. Uma retrospectiva histórica facilmente comprova os domínios dos Kaiowá nessa região de Mato Grosso do Sul, mas em nome do progresso e do desenvolvimento, o preconceito, o racismo, o etnocentrismo e a gula capitalista por terras, se intensifica mais e mais.

Um estudo da política indigenista atual, seguramente vai levar à conclusão de que a política assimilacionista continua atuando, agora com menor preocupação com a proteção dos povos indígenas brasileiros, jogando-os à mercê de garimpeiros, madeireiros e do agronegócio.

\section{REFERÊNCIAS}

BRIGHENTI, Clovis. Violência e desenvolvimento: o desenvolvimento versus os povos indígenas. In: CONSELHO INDIGENISTA MISSIONÁRIO [CIMI]. Relatório: violência contra os povos indígenas no Brasil. Brasília: CIMI, 2015.

CAIXETA, Fernando. Mourão sobre povos indígenas: "vivem em terras ricas como mendigos". Metrópoles, Brasília, 2020. Disponível em: https://www.metropoles.com/ brasil/politica-brasil/mourao-sobre-povos-indigenas-vivem-em-terras-ricas-comomendigos. Acesso em: 23 jul. 2021.

FUNAI. Assessoria de Planejamento e Coordenação. Projeto de desenvolvimento integrado de Panambi, ano agrícola 79/80 e 81/82. Brasília: Ministério do Interior/FUNAI, 1982. FUNAI. O índio e a ação da FUNAI. In: SEMANA DO ÍNDIO, 13-19 abr. 1981, Campo Grande, MS. Anais [...]. Campo Grande: 9a Delegacia Regional da FUNAl; Ministério do Interior; Governo de Mato Grosso do Sul, 1981.

FUNAI. Assessoria de Planejamento e Coordenação. Projetos elaborados safra de 1979/80. Brasília: Ministério do Interior/FUNAI, 1980.

FUNAI. Nova Filosofia. Boletim informativo da FUNAI, Brasília, ano 5, n. 17, 1976.

FUNAI. Desenvolvimento de projetos agropecuários nas áreas indígenas. Boletim Informativo da FUNAI, Brasília, ano 2, n. 8, 1973.

MEILLASSOUX, Claude. Mujeres, graneros y capitales: economia doméstica y capitalismo. Madrid: Siglo Veinteuno, 1977.

OLIVEIRA, Roberto Cardoso. A sociologia do Brasil indígena. Rio de Janeiro: Tempo Brasileiro, 1972. 
RIBEIRO, Darcy. Os índios e a civilização. 3. ed. Rio de Janeiro: Vozes, 1977.

SILVA, Joana A. Fernandes. Os Kaiowá e a ideologia dos projetos econômicos. Dissertação (Mestrado em Ciências Sociais) - Faculdade de Ciências Humanas e Sociais, UNICAMP, Campinas, 1982.

SURVIVAL. O que Jair Bolsonaro, Presidente-eleito, disse sobre os povos indígenas do Brasil. Survival, Goiânia, 2020. Artigos. Disponível em: https://www.survivalbrasil.org/ artigos/3543-Bolsonaro. Acesso em: 23 jul. 2021.

\section{Sobre a autora:}

Joana A. Fernandes Silva: Doutora em Antropologia Social pela Universidade de São Paulo (USP). Mestre em Ciências Sociais pela Universidade de Campinas (UNICAMP). Graduada em Ciências Sociais pela UNICAMP. Atualmente é professora titular aposentada, colaboradora do programa de pós-graduação em Antropologia Social e do curso de formação de professores indígenas da Licenciatura Intercultural Indígena na Universidade Federal de Goiás (UFG).E-mail: joana.fernandes@gmail. com, ORCID: https://orcid.org/0000-0002-1340-849X

Recebido em: 02/12/2020

Aprovado para publicação em: 16/12/2020 
